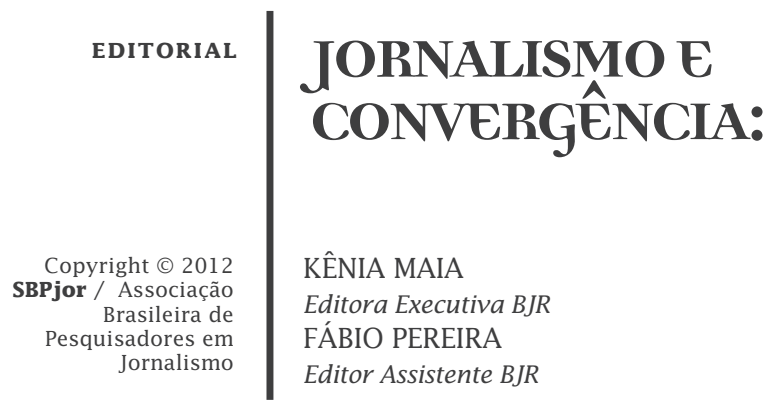

Nova palavra de ordem nos meios empresarial, profissional e acadêmico, a convergência tem sido utilizada para fazer referência a uma diversidade de processos: concentração dos grupos de comunicação, iniciativas de integração de redações e de distribuição de conteúdos em múltiplas plataformas, desenvolvimento de novos formatos de linguagem, reconfiguração das relações entre produtores e audiências etc. Como explica o pesquisador Canavilhas, no artigo que abre este dossiê, "podemos constatar uma tentativa de integrar as várias facetas da convergência, procurando uma definição chapéu capaz de abraçar todos os campos da convergência". De fato, para além de uma simples descrição técnica do fenômeno, o conceito de convergência tem se beneficiado de diferentes abordagens - econômica, sociológica, tecnológica, normativa - que explicam a diversidade de objetos e cenários descritos como convergentes.

A relação polissêmica e interdisciplinar que se estabelece em torno da convergência pode levar a um esvaziamento do conceito. Em alguns momentos, ele se confunde com um conjunto de variáveis que explicam os processos de transformação ou de reconfiguração de todo o sistema midiático. Isso explica a cautela dos autores que integram o dossiê Mídias Digitais, convergência e prática jornalística: desafios e perspectivas, desta edição da Brazilian Journalism Research. Alguns pesquisadores preferem utilizar terminologias mais precisas para descreverem fenômenos que emergem nesse cenário. É o que mostram os artigos de Alzamora e Tarcia e também de Pase, Nunes e Fontoura ao situarem a "narrativa transmídia" como um objeto de pesquisa que se coloca no âmbito do jornalismo convergente. Já Canavilhas prefere aplicar o conceito de "remediação" para descrever a transposição e adaptação de aspectos da linguagem digital pelas mídias tradicionais, o que seria distinto da convergência de conteúdos, definida como a utilização de 
"uma linguagem própria com características únicas e diferenciadas em relação ao restante dos meios".

Mais do que um jogo de linguagem, tais imprecisões em torno da definição de convergência permitem entender como as múltiplas apropriações do conceito podem ser utilizadas no sentido de produzir o que Pierre Bourdieu (1993; 1997) chama de "efeitos de realidade". A convergência é também um discurso que permite embasar processos concretos de reconfiguração da prática jornalística, nas relações que a organização midiática, os profissionais e as audiências estabelecem entre si e com os dispositivos tecnológicos. Nesse caso, o termo "convergente" pode ser utilizado para mascarar processos de concentração empresarial e de precarização na profissão. Ou pode remeter à eterna busca por formatos narrativos que materializem uma relação mais plural entre conteúdos e públicos - como descrevem Pase, Nunes e Fontoura em sua análise sobre o documentário transmídia Inside Desaster.

Vista sob esse prisma sociodiscursivo, a própria definição de convergência parece evoluir no tempo e no espaço. Em um estudo feito com base na leitura dos relatórios gerenciais do grupo canadense Québecor, Ancioux (2011) mostra as várias mudanças no uso da palavra convergência, frequentemente reapropriada com o objetivo de se adequar às mudanças nas estratégias empresariais da organização nas últimas duas décadas. Já o artigo de López García, Limia Fernández, Toural Bran e Pereira Fariña sobre o sistema midiático da Galícia, Espanha, evidencia em que medida o processo de convergência também se adapta em função do contexto local: "Percebemos claramente que o fenômeno convergente é toda uma realidade que afeta globalmente a mídia. No entanto, é um processo que também necessariamente atende às especificidades locais".

Na maioria das vezes, o termo convergência é utilizado para explicar um conjunto de inovações na prática jornalística. Nesse sentido, é importante entender de que forma o discurso da convergência também pode ser apropriado para encobrir o que Ruellan (2006) chama de realidades estruturais no jornalismo, que persistem, apesar do cenário de transformações. Essa relação entre mudança e conservação no jornalismo convergente está presente nos artigos de Canavilhas e de López García et al., e também no texto de Palacios, que aplica o conceito de Marginália, originalmente as anotações feitas pelos leitores nas margens de um texto, para situar os comentários do público na internet e suas possíveis implicações na construção da memória pelo jornalismo. 


\section{Organização do dossiê}

Abrem o dossiê Mídias Digitais, convergência e prática jornalística: desafios e perspectivas, os artigos que discutem os conceitos e cenários do jornalismo convergente. Os textos, "Da remediação à convergência: um olhar sobre os media portugueses", de João Canavilhas, e "Convergência $e$ Transmídia: galáxias semânticas e narrativas emergentes em Jornalismo", de Geane Alzamora e Lorena Tarcia, vão além de uma simples definição operacional da convergência e buscam o diálogo com processos mais específicos, "remediação" e "transmídia", o que permite enriquecer a compreensão do próprio cenário convergente. Dois artigos trabalham a convergência no contexto espanhol. "O estado dos blogs na mídia espanhola", redigido por Koldo Meso Ayerdi e Maria Bella Palomo Torres, mostra que, embora os grandes veículos midiáticos na Espanha ainda subestimem o jornalismo digital, os jornalistas blogueiros já se mostram preparados para ingressar no modelo da produção participativa. Já Xosé López García, Moisés Limia Fernández, Carlos Toural Bran e José Pereira Fariña, em "A Convergência como instrumento de renovação/conservação do jornalismo em Galícia: estratégias e indefinições", explicam em que sentido a relação entre global e local pode originar uma diversidade de interpretações sobre o processo convergente na Galícia.

Três artigos desenvolvem análises empíricas sobre a convergência a partir de objetos precisos. Em "Um tema e muitos caminhos: a comunicação transmidiática no jornalismo", André Fagundes Pase, Ana Cecília Bisso Nunes e Marcelo Crispim da Fontoura situam a narrativa transmídia como um processo cultural que materializa relações plurais entre conteúdos e audiências. Ao analisarem o documentário Inside desaster, os autores mostram como um novo formato narrativo abre a possibilidade de amplificar a experiência noticiosa no jornalismo. Já os artigos "O Enunciado Jornalístico no Twitter", de Mabel Oliveira Teixeira, e "Transformações do acontecimento nas redes sociais: das mobilizações contra a homofobia à crise de dupla sertaneja", de autoria de Ronaldo Cesar Henn, analisam as implicações do uso das redes sociais na construção da linguagem e da própria noção de acontecimento jornalístico.

Para encerrar este dossiê, foram escolhidos dois artigos de caráter mais ensaístico e que se voltam para as relações entre produtores e audiências. "Jornalismo Líquido: Tendências de ampliação do campo", de Anelise Rublescki e Alexandre Rocha da Silva descrevem um processo mais global de ampliação das fronteiras do campo, e analisa o fenômeno de mediação descentralizada no jornalismo. Marcos Palacios, em 
"Marginália, Zeitgeist e Memória do Tempo Presente: Os Comentários de Leitores no Ciberjornalismo", se interessa particularmente pelo caráter memorialístico dos comentários dos leitores e sua possível utilização historiográfica.

A seção de temas livres da $B J R$ traz três análises de cobertura noticiosa e retoma o debate sobre o papel do jornalismo na construção da realidade. Vicente William da Silva Darde e Valdir José Morigi, em "Diversidade Sexual no Jornalismo Brasileiro: Um estudo sobre as representações da população LGBT nos jornais Folha de S. Paulo e O Estado de S. Paulo", analisam a cobertura da aprovação da união estável entre pessoas de mesmo sexo pelo STF. Os autores concluem que o discurso da imprensa enquadrou o tema sob a perspectiva da heteronormatividade, reforçando valores e normas como "casamento" e adoção de crianças. "A depressão como objeto jornalístico: explorando o arquivo do Grupo Folha (1970-2009)", de Ericson Saint Clair, analisa as matérias de divulgação das pesquisas científicas acerca da depressão, um objeto pouco explorado nos estudos de jornalismo. O último artigo desta edição, "A cidade no jornalismo cultural: uma perspectiva de Porto Alegre na cobertura do Diário do Sul (1986-1988)", de Cida Golin, Sara Keller e Everton Cardoso, evidencia a forma como o jornal constrói e representa as diversas facetas da cidade, vista sobre o prisma da cultura como um espaço de novidade e atualização.

Os editores agradecem aos pareceristas que contribuíram com o processo de seleção dos textos, assim como a toda a equipe de produção editorial. Desejamos a todos uma proveitosa leitura.

\section{| REFERÊNCIAS}

ANCIAUX, A. Utilisation discursive et réalité de la 'convergence' au service d'un repositionnement du médiatique. Colóquio Internacional Mudanças Estruturais no Jornalismo (2011). Disponível em: <http:// www.mejor.com.br/index.php/mejor2011/MEJOR/paper/view/86/35>. Acesso em: 9 ago. 2012.

BOURDIEU, P. À propos de la famille comme catégorie réalisée. Actes de la recherche en sciences sociales, vol. 100, p. 32-36, décembre 1993. Disponível em: <http://www.persee.fr/web/revues/home/prescript/ article/arss_0335-5322_1993_num_100_1_3070>. Acesso em: 9 ago. 2012.

Sobre a Televisão. Rio de Janeiro: Jorge Zahar, 1997.

RUELLAN, D. Corte e costura do jornalismo. Líbero, v. 9, n. 18, p. 31-40, 2006. Disponível em: <http://www.revistas.univerciencia.org/index.php/ libero/article/view/4619>. Acesso em: 9 ago. 2012. 